\title{
TINJAUAN RETAK AWAL BALOK BETON BERTULANG YANG DIPERKUAT DENGAN STRAND TANPA PENEGANGAN
}

\author{
Heri Kasyanto ${ }^{1}$, Ambar Susanto ${ }^{2}$, Susilahadi ${ }^{3}$. \\ 1,2,3 Dosen Jurusan Teknik Sipil, Politeknik Negeri Bandung/Jl. Gegerkalong Hilir Ds.Ciwaruga Kotak pos \\ 1234 Bandung 40012, Indonesia \\ Email: 1 herikasyanto@polban.ac.id, ${ }^{2}$ susanto@polban.ac.id, ${ }^{3}$ susilahadi@polban.ac.id
}

\begin{abstract}
Reinforcing method of reinforced concrete beam has been done in Indonesia, one of them is by using of strand stressing. Strandstressing need additional technology so that strand reinforcing is not much in demand. Strand has high strength, so using strand needs to be modified in order to take advantage of the material. In this study, the strand will be used to reinforce of reinforced concrete beam by using epoxy and U-steel as anchors.

The research methodology based on experimental in the laboratory. The samples are consist of 3 specimens : the first is specimen without using of reinforcement (BU01), the second is specimen with reinforcement by using epoxy and $3 U$-steel as anchors(BU02), the third is specimen with reinforcement by using epoxy and $7 \mathrm{U}$-steel as anchors(BU03). Specimens dimensions of reinforced concrete beam are 150 $\mathrm{mm} \times 300 \mathrm{~mm}$ with a span of $3000 \mathrm{~mm}$.

The results show that the initial crack occurred in mid span beam on the pull side. The loads causing initial crack as follow: at $\mathrm{BU} 01=6.22 \mathrm{kN}$, at $\mathrm{BU} 02=3.95 \mathrm{kN}$ and at $\mathrm{BU} 03=0.25 \mathrm{kN}$. The results research show that initial cracking load of the specimen is inversely proportional with the number of anchor. If the number of anchor is greater, the cracking load will be smaller.
\end{abstract}

Keywords: reinforcement beam, steel of strand, initial crack

\begin{abstract}
ABSTRAK
Metode perkuatan balok beton bertulang sudah banyak dilakukan di Indonesia, salah satunya menggunakan baja strand yang ditegangkan. Penggunaan baja strand sebagai perkuatan masih terbatas dengan melakukan penegangan. Penegangan pada strand memerlukan teknologi tambahan sehingga perkuatan menggunakan strand tidak banyak diminati untuk perkuatan. Mengingat kekuatan strand yang tinggi maka pemanfaatan strand perlu dilakukan modifikasi agar dapat mengambil kelebihan dari material tersebut. Pada penelitian ini pemanfaatan strand digunakan untuk perkuatan balok bertulang tanpa dilakukan penegangan tetapi diikat dengan epoxy dan baja U yang diangkurkan ke balok beton bertulang. Metodologi penelitian yang digunakan menggunakan experimental di laboratorium. Benda uji terdiri dari 3 buah yaitu benda uji normal tanpa menggunakan perkuatan (BU01), benda uji dengan perkuatan strand tanpa penegangan yang diikat dengan epoxy dan 3 baja $U$ yang diangkurkan ke balok beton bertulang (BU02) dan benda uji dengan perkuatan strand tanpa penegangan yang diikat dengan epoxy dan 7 baja $U$ yang diangkurkan ke balok beton bertulang (BU03). Dimensi benda uji balok beton bertulang adalah 150 mm x 300 mm dengan bentang $3000 \mathrm{~m}$.

Hasil penelitian menunjukkan bahwa retak awal terjadi di tengah bentang (mid span) balok pada sisi tarik. Beban yang menyebabkan retak awal pada BU01 = 6,22 kN, BU02 = 3,95 kN dan BU03 = 0,25 kN. Hasil tersebut menunjukkan bahwa benda uji yang mempunyai lubang angkur untuk mengikat strand semakin banyak maka beban yang menyebabkan retak awal semakin kecil.
\end{abstract}

Kata Kunci : perkuatan balok, baja strand, retak awal

\section{PENDAHULUAN}

Perkembangan metode perkuatan balok beton bertulang sudah banyak dilakukan di Indonesia, seperti perkuatan dengan CFRP (Carbon Fiber Reinforcement Polymer), GFRP (Glass Fiber Reinforcement polymer), Wire Rope, Profil Baja Kanal sampai dengan metode prategang. Berbagai metode perkuatan yang sudah dikembangkan tersebut mempunyai kelebihan dan kekurangan. Kelebihan dari perkuatan tersebut adalah dapat meningkatkan kapasitas dari struktur yang diperkuat, adapun kelemahan antara lain kelemahan dari unsur material seperti terhadap suhu 
tinggi, mahalnya material perkuatan sampai kesulitan dalam metode pemasangannya.

Berdasarkan Nurlina dkk[1] balok yang diperkuat dengan CFRP mengalami peningkatan daktilitas sebesar 13,736\% jika dibandingkan dengan balok tanpa perkuatan dan daktilitas meningkat 31,859\% jika menggunakan perkuatan GFRP. Adapun penggunaan GFRP untuk perkuatan geser pada balok beton bertulang oleh Deskarta [2]telah merubah model keruntuhan dari keruntuhan geser menjadi keruntuhan lentur dan peningkatan beban yang dihasilkan sebesar $12,48 \%$ jika dibandingkan dengan balok beton bertulang tanpa berkuatan.Penggunaan Wire Rope untuk perkuatan balok bertulang penampang $\mathrm{T}$ juga dilakukan oleh Atmajayanti [3] dan Haryanto [4], Atmajayanti [3] melakukan analisis perkuatan dengan Wire Rope menggunakan modeling pada program response-2000 dan metode pias, rasio peningkatan kapasitas lentur masingmasing sebesar 1,01 dan 1,04 terhadap balok kontrol. Adapun hartanto [4] melakukan perkuatan dengan 2 Wire Rope pada daerah momen negatif menunjukkan kapasitas beban mengalami peningkatan dengan rasio sebesar 1,59.Menurut Miswar dan Pahlawan [5], perkuatan balok beton bertulang menggunakan profil baja kanal meningkatkan kapasitas lentur 37,858\% (profil baja kanal 70x30x1,2) jika profil dibesarkan maka peningkatan kapasitas semakin besar lagi tetapi berat sendiri struktur akan semakin besar pula. Wakid dkk [6] telah melakukan analisis kapasitas struktur atas jembatan komposit dengan metode prategang telah meningkatkan tegangan lentur sebesar $154,18 \%$.

Beberapa uraian tentang metode perkuatan diatas, bahwa perkuatan menggunakan prategang external adalah teknik yang efektif mengembalikan/meningkatkan kapasitas kekuatan strukturnya, hal ini tidak terlepas dari material yang digunakan mempunyai kekuatan tarik yang sangat tinggi yaitu material strand. Tetapi penegangan terhadap struktur pada kondisi existing, memerlukan peralatan dan teknik yang baik sehingga hasil yang diinginkan dapat tercapai. Melihat beberapa keunggulan strand yang mempunyai kuat tarik tinggi sehingga dari penelitian ini mencoba menggunakan material strand untuk perkuatan balok beton bertulang yang ditempel menggunakan epoxy dan dijepit oleh baja angkur berbentuk U.Karena beton adalah material yang baik menahan tekan tetapi lemah menahan tarik, sehingga pada beban tertentu beton sudah mulai mengalami retak (retak awal). Untuk itu dengan penambahan strand pada bagian tarik jugadiharapkan dapat meningkatkan beban saat terjadi retak awal, meskipun hal itu juga belum tentu dapat meningkatkan saat retak awal karena pada serat bawah balok beton terdapat lubang penempatan baja angkur $U$ yang menjepit strand.

Tujuan studi tentang tinjauan awal retak balok beton bertulang yang diperkuat dengan strand tanpa penegangan adalah:

a. Mendapatkan besaran beban yang menyebabkan terjadinya retak awal pada balok ketiga benda uji

b. Membandingan besaran beban yang menyebabkan retak awal pada ketiga benda uji balok beton bertulang

\section{METODA PENELITIAN}

Metode dalam penelitin ini menggunakan pengujian experimental di Laboratorium. Benda uji terdiri dari 3 buah yaitu:

a. BU01 adalah benda uji balok beton bertulang normal tanpa menggunakan perkuatan (Gambar 1)

b. BU02 adalah benda uji dengan perkuatan strand tanpa penegangan yang direkatkan dengan epoxy dan dijepit oleh 3 baja $U$ yang diangkurkan ke balok beton bertulang (Gambar 2)

c. BU03 adalah benda uji dengan perkuatan strand tanpa penegangan yang direkatkan dengan epoxy dan 
dijepit oleh 7 baja $\mathrm{U}$ yang diangkurkan ke balok beton bertulang (Gambar 3)

Dimensi benda uji balok beton bertulang adalah $150 \mathrm{~mm}$ x $300 \mathrm{~mm}$ dengan bentang
3000 m. Penampang balok beton bertulang untuk benda uji BU01, BU02 dan BU03 seperti pada Gambar 4.

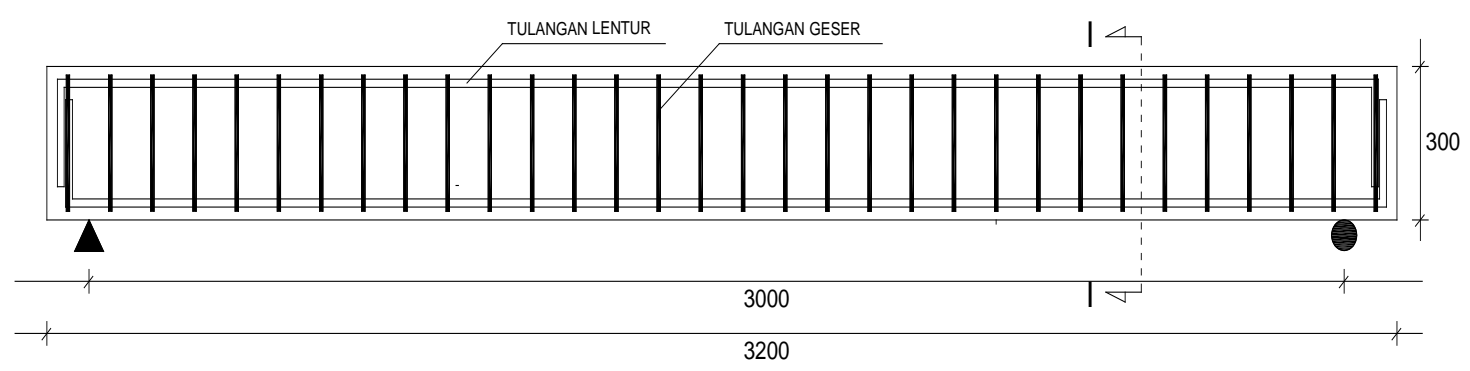

Gambar 1. Benda Uji BU01

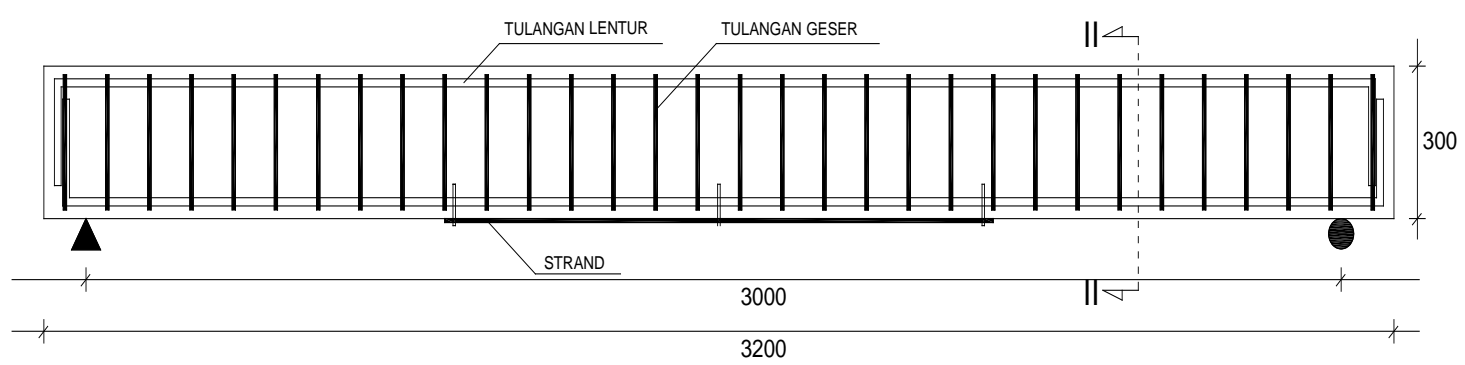

Gambar 2. Benda Uji BU02

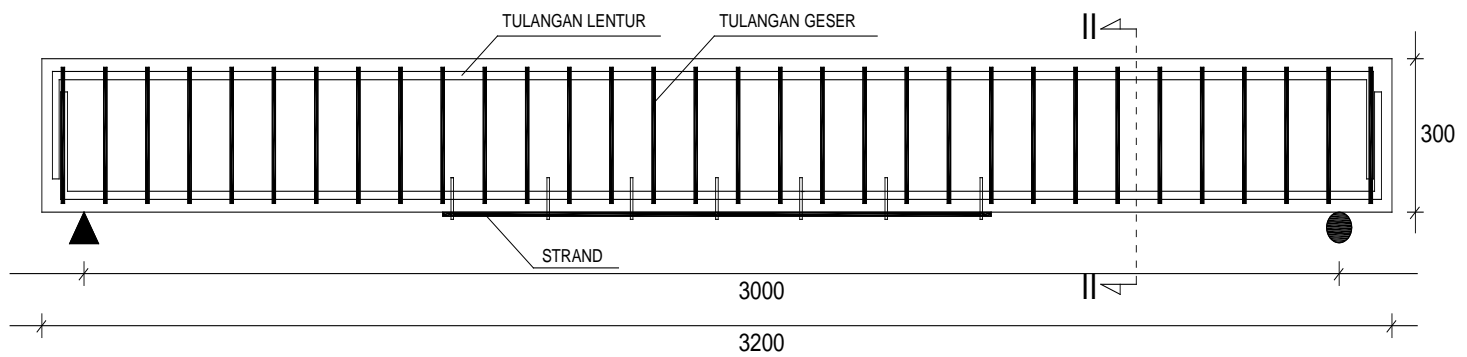

Gambar 3. Benda Uji BU03

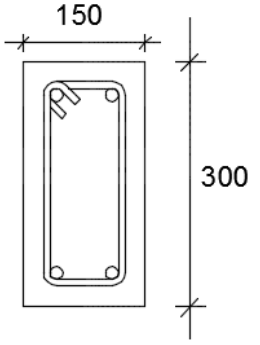

POT I-I

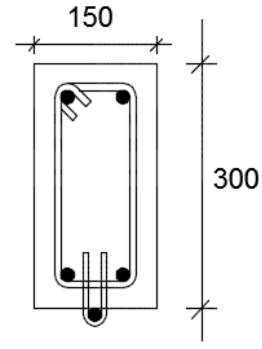

POT II-II

Gambar 4. Penampang Benda Uji BU01, BU02 dan BU03

Pengujian benda uji balok beton bertulang dilakukan setelah beton sudah mencapai umur 28 hari. Sistem pengujian menggunakan pembebananstatik- monotonik ditengah bentang. Skema pembebanan pada pengujian benda uji diuraikan seperti pada Gambar 5. 


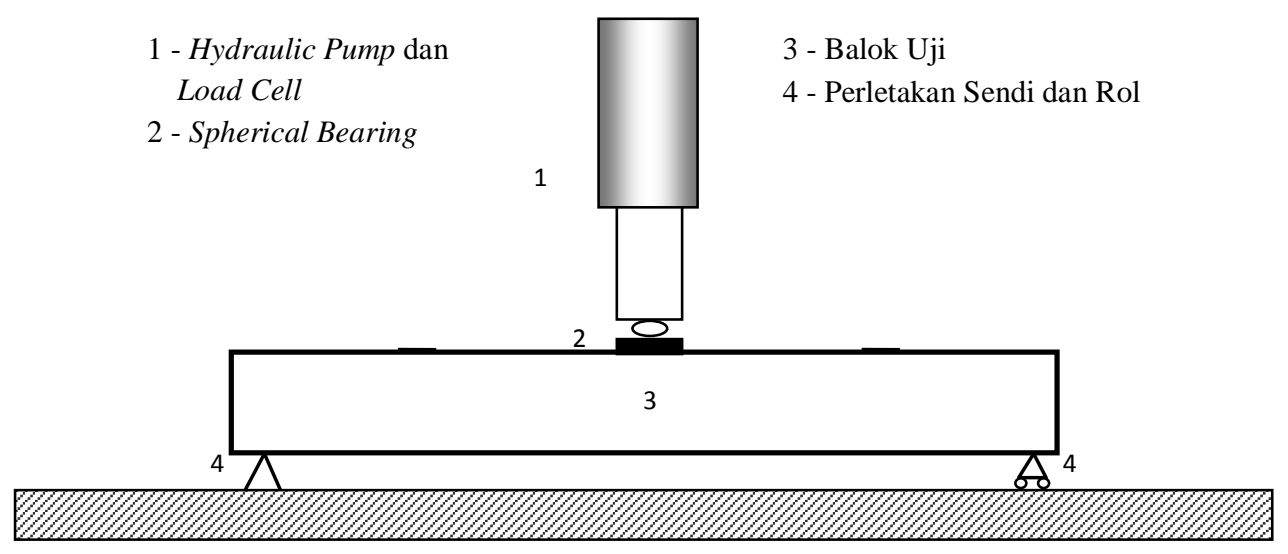

Gambar 5. Skema pembebanan statik-monotonik

\section{HASIL DAN PEMBAHASAN}

Pengujian mutu beton dan baja dilakukan uji tekan beton dan uji tarik baja dengan masing-masing berjumlah 3 benda uji. Hasil rata-rata dari pengujian tersebut diuraikan sebagai berikut:

a. Kuat tekan beton, $\mathrm{f}^{\prime} \mathrm{C}=16,57 \mathrm{MPa}$.

b. Kuat leleh baja diameter 13 , fy $=349$ MPa.

Hasil pengujian pada benda uji balok beton bertulang seperti pada Gambar 6 untuk benda uji BU01, Gambar 7 benda uji BU02 dan Gambar 8 benda uji BU03.

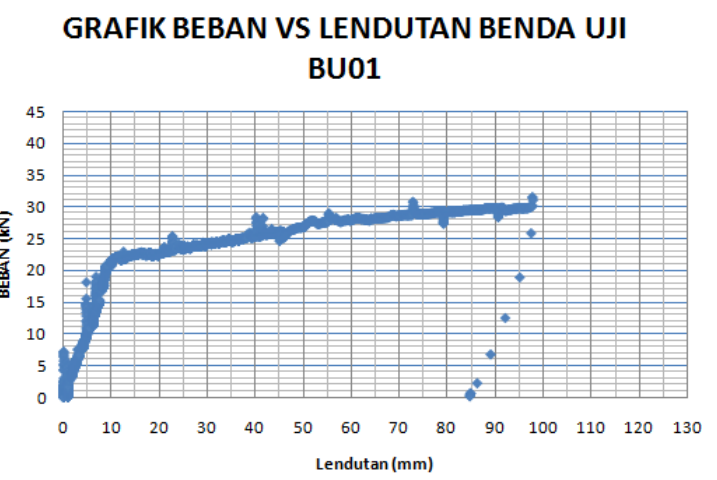

Gambar 6. Grafik Beban Lendutan pada Benda Uji BU01
GRAFIK BEBAN VS LENDUTAN BENDA I I BU02

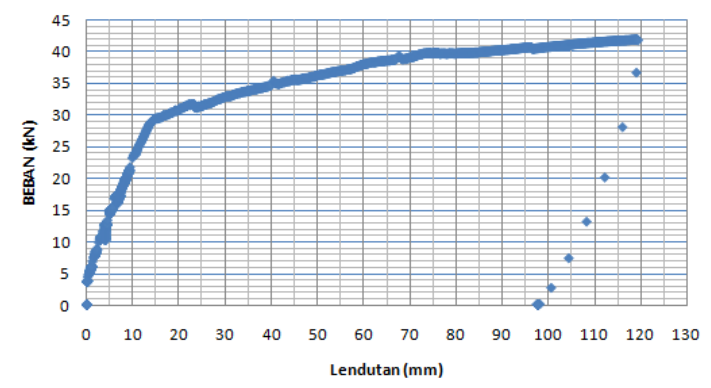

Gambar 7 Grafik Beban Lendutan pada Benda Uji BU02

\section{GRAFIK BEBAN VS LENDUTAN BENDA UJ} BU03

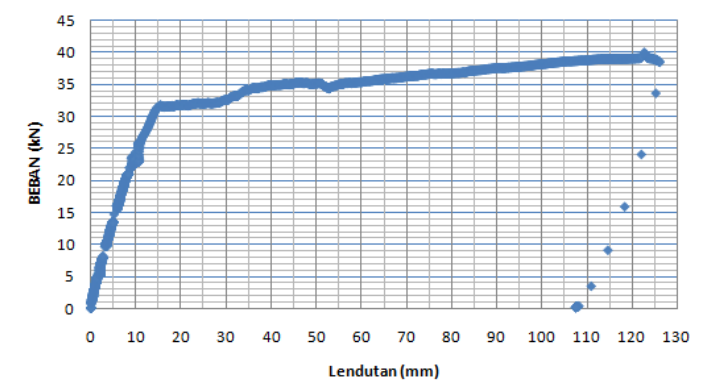

Gambar 8 Grafik Beban Lendutan pada Benda Uji BU03

Berdasarkan Park T dan Pauly $\mathrm{T}$ bahwa besarnya momen crack sebesar 5198450,493 Nmm, maka beban crack sebesar 6,238 kN. Beban pada retak awal diuraikan seperti Tabel 1 berikut. Beban leleh berdasarkan pada Gambar 6 sampai dengan Gambar 8 juga diuraikan seperti Tabel 1. 
Tabel 1. Besaran beban pada retak awal balok beton bertulang

\begin{tabular}{|c|c|c|c|c|}
\hline No & $\begin{array}{c}\text { Benda } \\
\text { Uji }\end{array}$ & $\begin{array}{c}\text { Regangan } \\
\text { crack } \\
\text { awal } \\
(\mu \mathrm{m} / \mathrm{m})\end{array}$ & $\begin{array}{c}\text { Beban } \\
\text { crack } \\
\text { awal } \\
(\mathrm{kN})\end{array}$ & $\begin{array}{c}\text { Beban } \\
\text { leleh } \\
(\mathrm{kN})\end{array}$ \\
\hline 1 & BU01 & 47,073 & 6,22 & 19,995 \\
\hline 2 & BU02 & 57,501 & 3,95 & 29,028 \\
\hline 3 & BU03 & 47,080 & 0,25 & 32,026 \\
\hline
\end{tabular}

Berdasarkan Tabel 1 bahwa benda uji dengan semakin banyak angkur baja $U$ maka besaran beban yang menyebabkan retak awal semakin kecil, hal ini berkebalikan dengan besaran beban leleh semakin besar. Penelitian Ujianto [6] juga menyatakan bahwa beban retak awal menurun sejalan dengan besarnya lubang, hal ini karena berkaitan dengan banyaknya lubang angkur untuk penempatan baja $U$ sehingga beban retak awal semakin kecil. Pola retak benda uji juga ditunjukkan bahwa benda uji tanpa perkuatan BU01 jumlah retak lebih sedikit jika dibandingkan dengan benda uji dengan perkuatan dan jumlah angkur baja U. Semakin banyak jumlah angkur baja U maka jumlah retak semakin banyak seperti Gambar 9 sampai dengan Gambar 11.

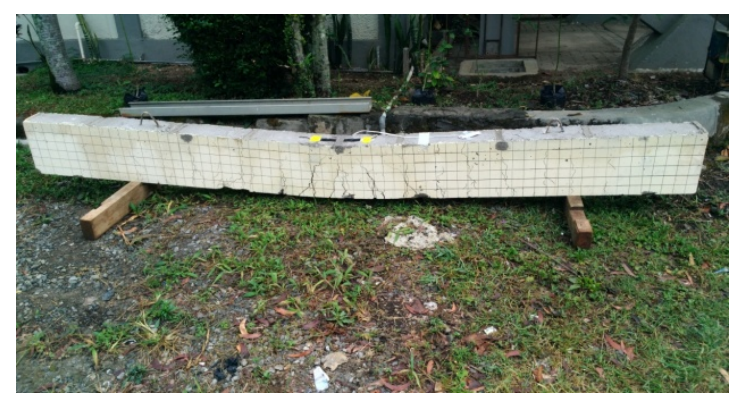

Gambar 9. Pola retak benda uji BU01

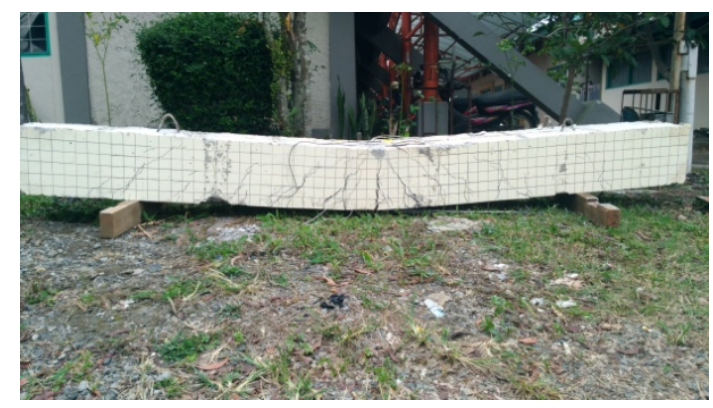

Gambar 10. Pola retak benda uji BU02

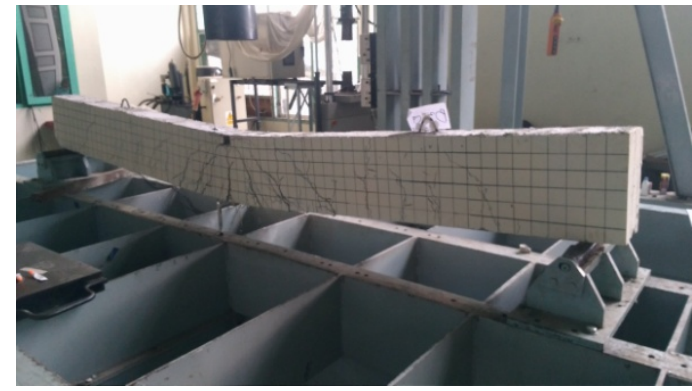

Gambar 11. Pola retak benda uji BU03

\section{KESIMPULAN}

Dari pembahasan di atas dapat ditarik kesimpulan sebagai berikut:

a. Retak awal terjadi di tengah bentang balok pada sisi tarik.

b. Beban yang menunjukkan retak awal pada benda uji BU01 $=6,22 \mathrm{kN}$, $\mathrm{BU} 02=3,95 \mathrm{kN}$ dan $\mathrm{BU} 03=0,25$ $\mathrm{kN}$.

c. Pembeda antara benda uji adalah banyaknya lubang untuk memasukkan angkur sehingga semakin banyak lubang untuk penempatan angkur maka beban yang menyebabkan retak awal semakin kecil.

\section{DAFTAR PUSTAKA}

[1] Nurlina S, Suseno. H, Hidayat M.T, Pratama I.M.Y. 2016. "Perbandingan Daktilitas Balok Beton Bertulang Dengan Menggunakan Perkuatan CFRP dan GFRP”. Rekayasa Sipil, Volume 10 No.1 - 2016, ISSN 19785658.

[2] Deskarta. 2009. "Perkuatan Geser Balok Beton Bertulang Menggunakan Glass Fiber Reinforced Polymer (GFRP). Jurnal Ilmiah Teknik Sipil, Volume 13 No 2, Juli 2009.

[3] Atmajayanti A.T. 2013. “Analisis Balok Beton Bertulang Tampang T yang Diperkuat dengan Wire Rope Menggunakan Program Response2000 dan Metode Pias”. Dinamika Rekayasa, Volume 9 No.1 Februari 2013, ISSN 1858-3075.

[4] Haryanto Y. 2011. "Efektifitas Wire Rope sebagai Perkuatan pada 
Heri Kasyanto dkk, Tinjauan Retak Awal Balok Beton Bertulang...

Daerah Momen Negatif Balok

Beton Bertulang Tampang T".

Dinamika Rekayasa, Volume 7 No.

2 Agustus 2011, ISSN 1858-3075

[5] Miswar K, Pahlawan T, Perbaikan

dan Perkuatan Balok Beton

Bertulang dengan Cara Penambahan

Profil Baja Kanal, Teknik Sipil, Politeknik Negeri Lhokseumawe, NAD.

[6] Wakid M, Kristiawan SA, Rahmadi A.P. 2014. "Perkuatan Struktur Atas Jembatan Komposit dengan Metode Prategang Eksternal”. Jurnal Teknik Sipil, Magister Teknik Sipil Universitas Sebelas Maret, Volume II No.1 Maret 2014, ISSN 23390271.

[7] Ujianto M. 2007. Perilaku Retak Beton Bertulang Akibat Pembuatan Lubang di Badan, Dinamika Teknik Sipil, Volume 7, No.2, Juli 2007 : 109-116. 